\title{
Effect of Geometric Design and Materials on Section Properties of Additively Manufactured Lattice Elements
}

\author{
Abduladheem Almalki ( $\sim$ s3795686@student.rmit.edu.au ) \\ RMIT University
}

\section{David Downing}

ARC Training Centre in Additive Biomanufacturing

Bill Lozanovski

ARC Training Centre in Additive Biomanufacturing

Rance Tino

Peter MacCallum Cancer Centre

Ahmad Alghamdi

Umm Al Qura University

Ma Qian

RMIT University

Milan Brandt

ARC Training Centre in Additive Biomanufacturing

Martin Leary

ARC Training Centre in Additive Biomanufacturing

\section{Research Article}

Keywords: Laser-Based Powder Bed Fusion (LB-PBF), Additive Manufacturing (AM), Metal Additive Manufacturing (MAM), Computed Tomography (CT), Additive Manufacturing Defects, Design For Additive Manufacturing (DFAM)

Posted Date: February 1st, 2022

DOI: https://doi.org/10.21203/rs.3.rs-1295349/v1

License: (1) (1) This work is licensed under a Creative Commons Attribution 4.0 International License.

Read Full License 


\title{
Effect of geometric design and materials on section properties of additively manufactured lattice elements
}

\author{
Abduladheem Almalki ${ }^{1}$, David Downing ${ }^{1,2}$, Bill Lozanovski ${ }^{1,2}$, Rance Tino ${ }^{1,2,3}$ \\ Ahmad Alghamd 4 , Ma Qian ${ }^{1}$, Milan Brandt 1,2, Martin Leary 1,2 \\ 1: RMIT Centre for Additive Manufacture, RMIT University, \\ Melbourne Australia, martin.leary@rmit.edu.au \\ 2: ARC Training Centre in Additive Biomanufacturing, \\ www.additivebiomanufacturing.org \\ 3. Peter MacCallum Cancer Centre, Melbourne, Australia \\ 4. Umm Al Qura University, Makkah, Saudi Arabia
}

\begin{abstract}
Additive Manufacturing (AM) technologies such as Laser-Based Powder Bed Fusion (LB-PBF) enables fabrication of complex lattice structures. However, LB-PBF processes inherently induce dimensional variation between idealised and as-manufactured specimens. This research proposes and implements a method to characterise the structurally relevant geometric properties of as-manufactured strut elements; as demonstrated to characterise the effect of LBPBF material (aluminium alloy and titanium) and geometric design parameters (polygon order, effective diameter and inclination angle) on the stiffness and strength of as-manufactured strut elements. Micro-computed tomography is applied to algorithmically characterise the asmanufactured variation and identify a threshold below which additional geometric resolution does not result in increased part quality. This methodology provides an algorithmic and robust Design for AM (DFAM) tool to characterise the effect of manufacturing and design parameters on the functional response of AM strut elements, as is required for certification and optimisation.
\end{abstract}

Keywords: Laser-Based Powder Bed Fusion (LB-PBF), Additive Manufacturing (AM), Metal Additive Manufacturing (MAM), Computed Tomography (CT), Additive Manufacturing Defects, Design For Additive Manufacturing (DFAM). 
NOMENCLATURE

\begin{tabular}{|l|l|}
\hline Term & Definition \\
\hline AM & Additive Manufacturing \\
\hline CAD & Computer Aided Design \\
\hline DFAM & Design for Additive Manufacturing \\
\hline LB-PBF & Laser-Based Powder Bed Fusion \\
\hline MAM & Metal Additive Manufacturing \\
\hline MCT & Micro-Computed Tomography \\
\hline DOE & Design of Experiment \\
\hline PBS & Powder bed system \\
\hline PFS & Powder feed system \\
\hline WFS & Wire feed system \\
\hline SEM & Scanning electron microscope \\
\hline SLM & Selective laser machine \\
\hline IQR & Interquartile range (statistics) \\
\hline
\end{tabular}

\section{SYMBOLS}

\begin{tabular}{|l|l|}
\hline Term & Definition \\
\hline$R_{g}$ & Radius of gyration $[\mathrm{mm}]$ \\
\hline$I$ & Second moment of area $\left[\mathrm{mm}^{4}\right]$ \\
\hline$I_{\text {ideal }}$ & Second moment of area for idealised case $\left[\mathrm{mm}^{4}\right]$ \\
\hline$I_{C T}$ & Second moment of area for as-manufactured case $\left[\mathrm{mm}^{4}\right]$ \\
\hline$I_{C T \text { max }}$ & Maximum second moment of area for as-manufactured case $\left[\mathrm{mm}^{4}\right]$ \\
\hline$I_{C T \text { min }}$ & Minimum second moment of area for as-manufactured case $\left[\mathrm{mm}^{4}\right]$ \\
\hline$\left.A_{\text {ideal }}\right]$ & Cross-seconal area for idealised case $\left[\mathrm{mm}^{2}\right]$ \\
\hline$A_{C T}$ & Cross-seconal area for as-manufatured case $\left[\mathrm{mm}^{2}\right]$ \\
\hline$\alpha$ & Inclination angle $\left[^{\circ}\right]$ \\
\hline$D_{e f f}$ & Effective diameter $[\mathrm{mm}]$ \\
\hline$P$ & Number of polygon \\
\hline$\theta$ & Rotation angle $\left[{ }^{\circ}\right]$ \\
\hline
\end{tabular}




\begin{tabular}{|c|c|}
\hline$R_{\text {gideal }}$ & Radius of gyration for idealised [mm] \\
\hline$R_{g C T}$ & Radius of gyration for as-manufactured case [mm] \\
\hline$p$ & Polygon order \\
\hline$s$ & Polygon side length $[\mathrm{mm}]$ \\
\hline$\emptyset_{B}^{e}$ & Elastic bending shape factor \\
\hline$\emptyset_{B}^{f}$ & Failure bending shape factor (associated with yield) \\
\hline$Z$ & Section modulus $\left[\mathrm{mm}^{3}\right]$ \\
\hline$Z_{\text {circle }}$ & Circler section modulus $\left[\mathrm{mm}^{3}\right]$ \\
\hline
\end{tabular}




\section{INTRODUCTION}

Additive Manufacturing ( $A M)$ enables the layer-by-layer fabrication of three-dimensional geometry directly from CAD data using a common source material, thereby providing potential advantages over conventional manufacturing [1]. For example, AM can fabricate complex topology optimised geometry as a single structure, whereas conventional manufacturing may be constrained by the need for tooling access [2]. Despite these advantages, the AM processes is subject to a series of technical challenges including: limited production rate, thermal stresses, potentially high material cost and geometric uncertainties in the as-manufactured geometry [3]. Metal Additive Manufacturing (MAM) enables fabrication with a range of fusible metal alloys including light alloys, superalloys, and tools steels. MAM enables the fabrication of high-value lattice applications including medical implants, aerospace components and custom tooling [4]. Although understanding MAM manufacturing defects of individual lattice strut elements is required to optimise mechanical performance, few fundamental studies have been executed. In response to this identified deficiency, a fundamental methodology is proposed to algorithmically quantifying the manufacturability and cross-sectional geometric properties for as-manufactured strut elements. This methodology is demonstrated with a design of experiment (DOE) that considers a range of design-relevant control factors including strut element inclination angle, $\alpha$, cross-sectional shape (including circular, square, octagon, triangular pointing up and pointing down), as well as material type, including aluminium (AlSi10Mg) and titanium (Ti6Al4V) strut elements fabricated by Laser-Based Powder Bed Fusion (LB-PBF). Micro-computed tomography $(\mu \mathrm{CT})$ imaging techniques are applied to enable the algorithmic characterisation of the geometric attributes of these as-manufactured lattice strut elements [5]. This outcome contributes to the fundamental understanding of analytical and as-manufactured quantification methods for additively manufactured strut elements, thereby providing a robust Design For AM (DFAM) tool for lattice certification and structure optimisation.

\subsection{METAL ADDITIVE MANUFACTURING}

Metal Additive Manufacturing (MAM) is a sub-classification of AM processes that sequentially fabricate a three-dimensional metal component based on digital Computer Aided Design (CAD) data $[6,7]$. MAM fabrication is typically achieved by the iterative fusion of metallic input material for a series of cross-sectional layers based on digital design data [8]. MAM provides an opportunity to fabricate novel, lightweight, and high-value components such as medical implants and lightweight aerospace components. MAM processes can be classified into three primary systems: Powder Bed Fusion (PBF), powder feed system (PFS), and wire feed system (WFS) [4]. In this research, laser-based PBF (LB-PBF) is used to fabricate the individual strut element specimens due to the compatibility of this method with the manufacture of high-resolution features with a relatively high degree of dimensional control [9]. 


\subsubsection{MAM DEFECTS ASSOCIATED WITH LB-PBF}

As for any manufacturing process, defects occur during the AM process; in this case, due to many physical processes and process parameters involved, such as laser power, scan speed, hatch spacing, powder material, and layer thickness [10]. Echeta et al. [11] classified LB-PBF defects into three categories: porosity or incomplete fusion, residual stresses, and surface texture. Zhang et al. [10] defines this porosity as spheroidal voids within fused powder, where the pore diameter is up to approximately $100 \mu \mathrm{m}$. This porosity is formed due to high cooling rates during solidification, leading to dissolved gas that cannot escape from the melt pool. Additionally, insufficient input energy may lead to incomplete fusion and can result in pores of the order of $500 \mu \mathrm{m}$. Residual stresses are formed during the PBF processes due to rapid heating and cooling rates that can cause cracking in the lattice structure [12]. Furthermore, shrinkage occurs on cooling of the melt pool potentially leading to surface cracking. Surface texture variation is observed on the AM lattice structures, which is caused by several phenomena. The layer-wise fabrication of the MAM strategy inherently leads to the stair-stepping phenomenon [11]. It is clearly observed on surfaces inclined to the build direction, with characteristic surface roughness on the inclined surface of a lattice structure [5]. The magnitude of roughness on upward and downward struts is a function of inclination angle as well as the associated process parameters. This as-manufactured roughness may provide advantages in biomedical applications where it can be beneficial for cell attachment [13].

The primary commercial opportunity for AM production is typically for high-value applications; consequently, methods to predict and quantify the magnitude of AM defects in as-manufactured components are of critical importance. Echeta et al. [11] comprehensively reviewed the primary measurement methods available for quantifying MAM defects. These methods include microcomputed tomography $(\mu \mathrm{CT})$, scanning electron microscope (SEM), physical measurement, optical microscopy, and Archimedes' methods. Each one of these methods has a specific set of capabilities for quantifying certain attributes of observed manufacturing defects. In this research, $\mu C T$ provides a robust tool to quantify the MAM geometric defects and associated section properties for AM analysis.

\subsection{MECHANICAL RESPONSE OF LATTICE STRUT ELEMENTS}

In a lattice structure, the mechanical response and associated strut element loading varies depending upon the unit cell topology and associated loading conditions. The strut element loading can be categorised as being either bending or stretch dominated [14]; resulting in strut elements subjected predominantly to bending (Figure 1.a) or axial loads (Figure 1.2), respectively. The structural response of the lattice is determined by Maxwell's criterion which considers the lattice as a mechanical linkage and estimates the structural determinacy associated with the numbers of strut and node elements [15]. Strut element cross-section properties contribute 
substantially to structural response, especially for bending and buckling modes. This research provides insight into the structural efficiency of as-manufactured strut elements according to the associated material and geometric design parameters.

a)

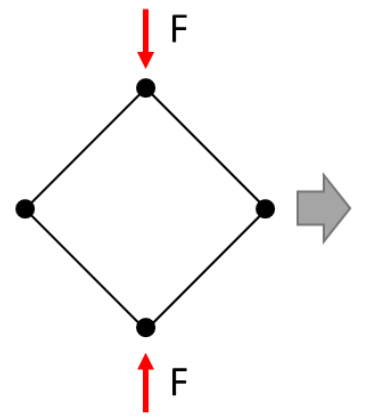

b)

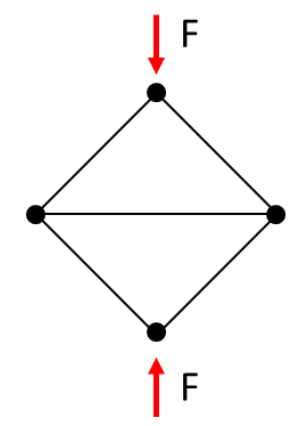

Compression

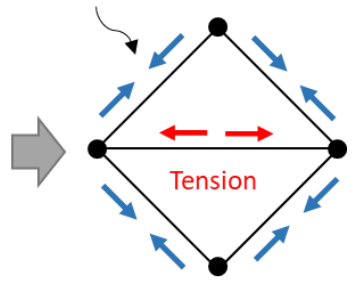

Figure 1: Bending-dominated (a) and stretch-dominated (b) mechanical response of lattice strut elements [16].

\subsection{STRUT CROSS-SECTION MANUFACTURABILITY}

Alghamdi et al. [17] investigated the effect of polygon order (triangular, square, octagonal, and circular) on the geometry of as-manufactured lattice strut elements fabricated with LB-PBF in aluminium and titanium. They observed the tendency for nominally triangular and square crosssections to become circular upon fabrication (as quantified by the isoperimetric quotient). This observed effect was particularly strong for aluminium material (as opposed to titanium) and for relatively small cross-sectional area. Furthermore, triangular cross-sections were observed to have greater manufacturability when the triangle is oriented with a vertex pointing downward toward the build platen and a flat surface pointing upward, compared to the triangle oriented with a vertex pointing upward and the flat surface pointing downward toward the build platen. This research proposes to extend the findings of prior investigations to characterise the functional response of as-manufactured strut elements.

\section{GEOMETRIC PROPERTIES OF POLYGON'S CROSS-SECTION}

Cross-section properties can be used to characterise structural design efficiency, including: second moment of area, radius of gyration, section modulus, elastic shape factor, and failure shape factor. These properties will be acquired to analytically compare the efficiency of the specimens assessed in this research, and are briefly defined below.

\subsection{SECOND MOMENT OF AREA}

The second moment of area is a measure of the distribution of the area for a given cross-sectional column or beam [18]. It is useful to quantify the capacity of a column to resist buckling and for a beam to resist bending. A second moment of area, $I$, is defined as the integral sum (Eq. 1) of 
infinitesimal area, $\delta A$, a distance, $y$, from the neutral axis [19]. For many regular polygon shapes, such as a circle (Eq. 2), the second moment of area calculated analytically based on a specific formula, however, these formulas are limited to specific shapes. Therefore, a general equation (Eq. 3) is introduced which can be used to obtain the second moment of area for any irregular nsided polygon ${ }^{1}[20]$.

$$
\begin{aligned}
& I=\int y^{2} d A \\
& I_{\text {circle }}=\frac{\pi}{4} r^{4} \\
& I_{\text {polygon }}=\frac{1}{12} \sum_{i=1}^{n}\left(x_{i} y_{i+1}-x_{i+1} y_{i}\right)\left(x_{i}^{2}+x_{i} x_{i+1}+x_{i+1}^{2}\right)
\end{aligned}
$$

\subsection{RADIUS OF GYRATION}

The radius of gyration, $R_{g}$, defines a theoretical offset from the cross-section centroid at which the entire mass can be imagined to exist with the same moment of inertia, $I$, as the actual crosssection (Figure 2. b) [19]. It measures the elastic resistance of cross-sectional beam to buckling or bending [21]; and can therefore be useful to compare how different shapes associated with the same cross-sectional area behave under loading that induces buckling or bending (Eq. 4). For example, comparing $R_{g}$ for triangular versus circular cross-sections indicates that triangular sections have larger $R_{g}$, and are therefore more efficiently able to resist elastic buckling or bending.

$$
R_{g}=\sqrt{\frac{I}{A}}
$$

\footnotetext{
${ }^{1}$ The polygon points should be ordered in a counter-clockwise direction, voids can be included through clockwise ordering.
} 
a)

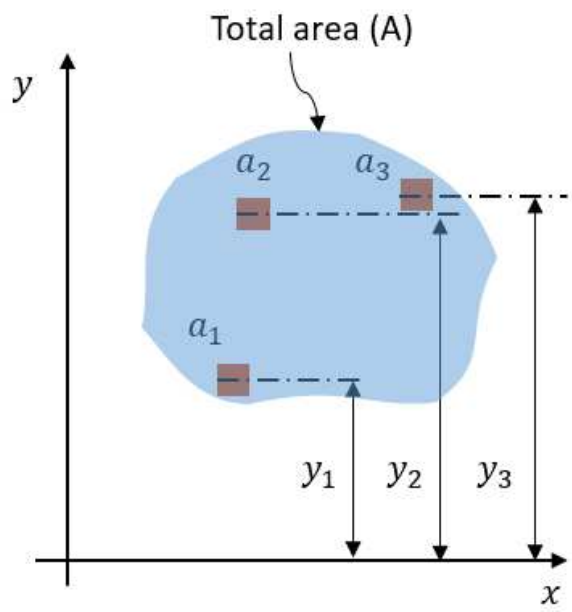

b)

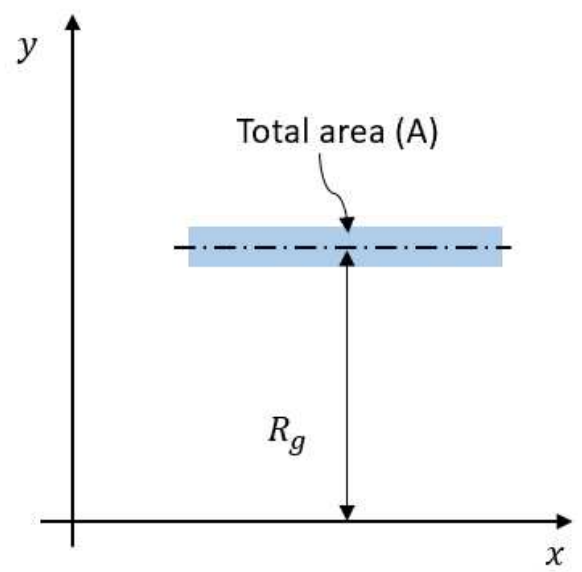

Figure 2: Radius of gyration schematic diagram.

Comparing a) distances, $y_{i}$, from the $x$-axis for incremental areas in the same cross-section, $b$ ) Equivalent area in a thin strip offset by the radius of gyration, $R_{g}$, from the $x$-axis.

\subsection{ELASTIC AND FAILURE SHAPE FACTORS FOR BENDING}

The shape factor, $\emptyset$, compares the mechanical performance (such as buckling or bending) of a cross-sectional area against a reference circular cross-section associated with the same area [22]. The shape factor of a solid circular cross-section is unity and as this number increases, the resistance to bending increases. In addition, shape factors are dimensionless which allow better comparison across different scales, allowing comparison of shape independent of strut element size.

The influence of cross-sectional shape on stiffness can be calculated using the elastic bending shape factor, $\emptyset_{B}^{e}$ (Eq. 5). However, strength in bending depends on the local stress; and to quantify the bending failure shape factor, $\emptyset_{B}^{f}$, for yield, the section modulus, $Z$, needs to be calculated (Eq. 6) where $y_{\max }$ is the furthest point from the neutral axis. The bending failure shape factor, $\emptyset_{B}^{f}$, is the ratio of any given section modulus, $Z$, over the solid section modulus, $Z_{\text {circle }}$, with a circle of equal area (Eq. 7).

$$
\begin{aligned}
& \emptyset_{B}^{e}=\frac{4 \pi I}{A^{2}} \\
& Z=\frac{I}{y_{\max }} \\
& \emptyset_{B}^{f}=\frac{4 \sqrt{\pi} Z}{A^{3 / 2}}=\frac{Z}{Z_{\text {circle }}}
\end{aligned}
$$

Structural performance in bending can therefore be characterised by selecting an appropriate combination of material and shape for both elastic and plastic scenarios [22]. By inspection, the 
solid triangular cross-section under bending load is stiffer than an equivalent solid circular crosssection by $21 \%$, whereas it has $23 \%$ lower strength.

\subsection{EFFECTIVE DIAMETER}

Effective diameter, $D_{e f f}$, represents the diameter of a circle that has an equivalent area to the area of the polygon. In this research, four effective diameters are implemented $(3.0 \mathrm{~mm}, 2.0 \mathrm{~mm}$, $1.0 \mathrm{~mm}, 0.5 \mathrm{~mm}$ ) on different polygonal shapes associated with equal area. For these cases, the polygon's side length, $s$, and $D_{e f f}$ are presented in [1], and the effective diameter is illustrated in Figure 3.

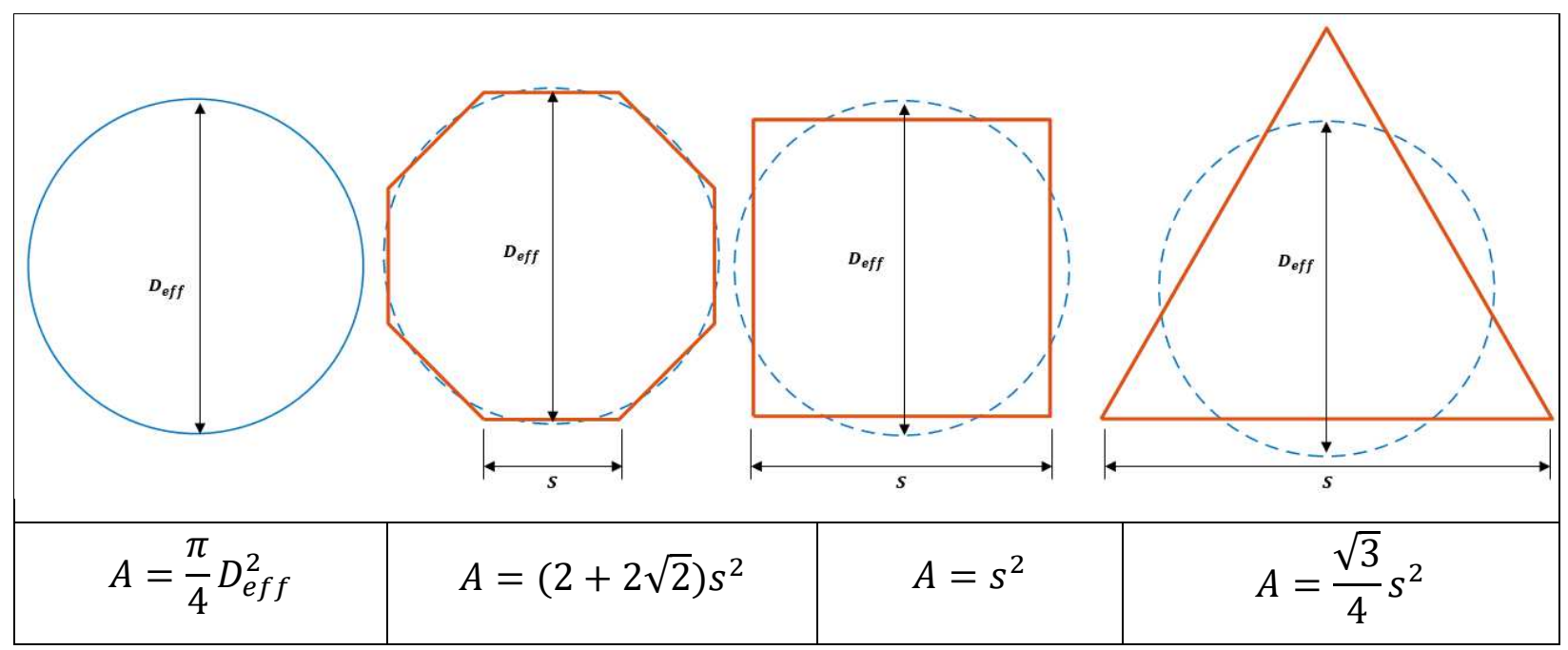

Figure 3 Systematic diagram for effective diameter, $D_{e f f}$, of polygon shapes associated with equal area.

\section{METHOD}

In recent literature reviews, there exist significant limitations on DFAM tools that can quantify the structural integrity of as-manufactured AM strut elements. Cross-sectional design has a significant impact on strut performance; thus, shape factor should be characterised to assess the strength and stiffness of proposed designs. This research proposes a fundamental methodology for the characterisation of as-manufactured strut elements to quantify the associated geometric and functional properties. This generalisable DFAM tool is implemented specifically on strut elements specimens fabricated by PB-LBF. Figure 4 displays the proposed methodology's primary phases, which can be applied as a guideline to any manufacturing process to ensure optimal production and certification. The proposed method can be classified into the following main steps: CAD design, analytical quantification, PB-LBF fabrication, X-ray micro-computed tomography, as-manufactured quantification, and statistical analysis. 


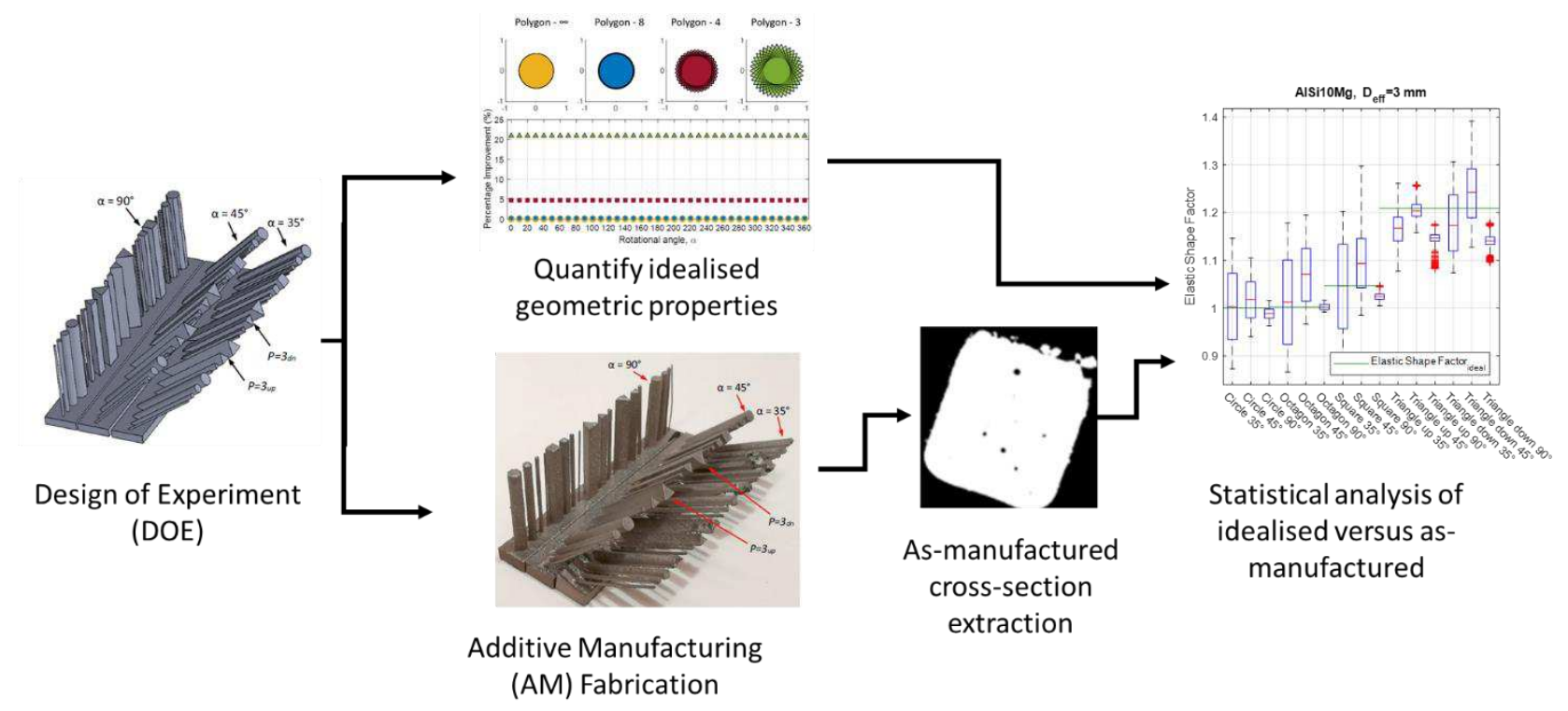

Figure 4: The flow chart of proposed method of quantifying cross-section structural properties for idealised and as-manufactured strut elements [5].

\subsection{DESIGN OF EXPERIMENTS}

The design of experiments (DOE) contains four controlling factors including two types of materials (aluminium and titanium), three inclination angles $\left(\alpha=90^{\circ}, 45^{\circ}, 35^{\circ}\right)$, four nominal diameters $(D=3.0,2.0,1.0,0.5 \mathrm{~mm})$, and four polygonal cross-sections (circle, octagon, square, triangle vertex up, triangle vertex down).

\subsection{LASER-BASED POWDER BED FUSION AND MICRO-COMPUTED TOMOGRAPHY}

The total number of specimens is 120 and were fabricated by LB-PBF using aluminium (AlSi10Mg) and titanium (Ti6Al4V) with process parameters provided in Table 1. Once the specimens were fabricated, micro-computed tomography $(\mu \mathrm{CT})$ was used to $3 \mathrm{D}$ image the as-manufactured strut elements individually, reaching a voxel size of $8 \mu \mathrm{m}$ [5]; in this research, the grey-scale crosssectional images were used to identify the strut element boundary and quantify the asmanufactured sectional properties. 
Table 1: LB-PBF parameters and associated powder size profile for both Ti6Al4V and AlSi10Mg.

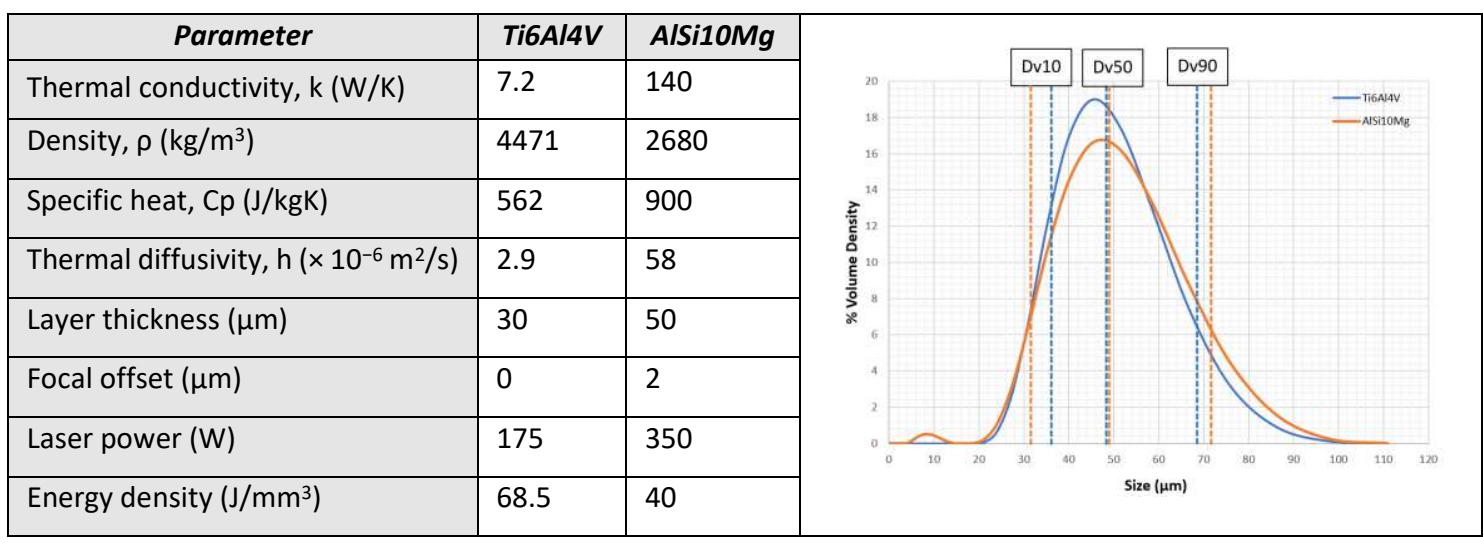

\subsection{ALGORITHMIC IMPLEMENTATION}

The cross-sectional geometric properties for both idealised and as-manufactured cases are calculated using a custom developed MATLAB script. The code starts by obtaining the idealised properties based on the polygon order for the DOE. Then, $\mu \mathrm{CT}$ cross-sectional images for the asmanufactured case are imported and converted into binary images and from this data the geometric properties are calculated as a function of the angular orientation of the cross-section about its centroidal axis (Figure 5). To provide statistical distributions of cross-sectional response, this method is repeated for a number of sequential $\mu C T$ cross-sectional images within the image stack. 

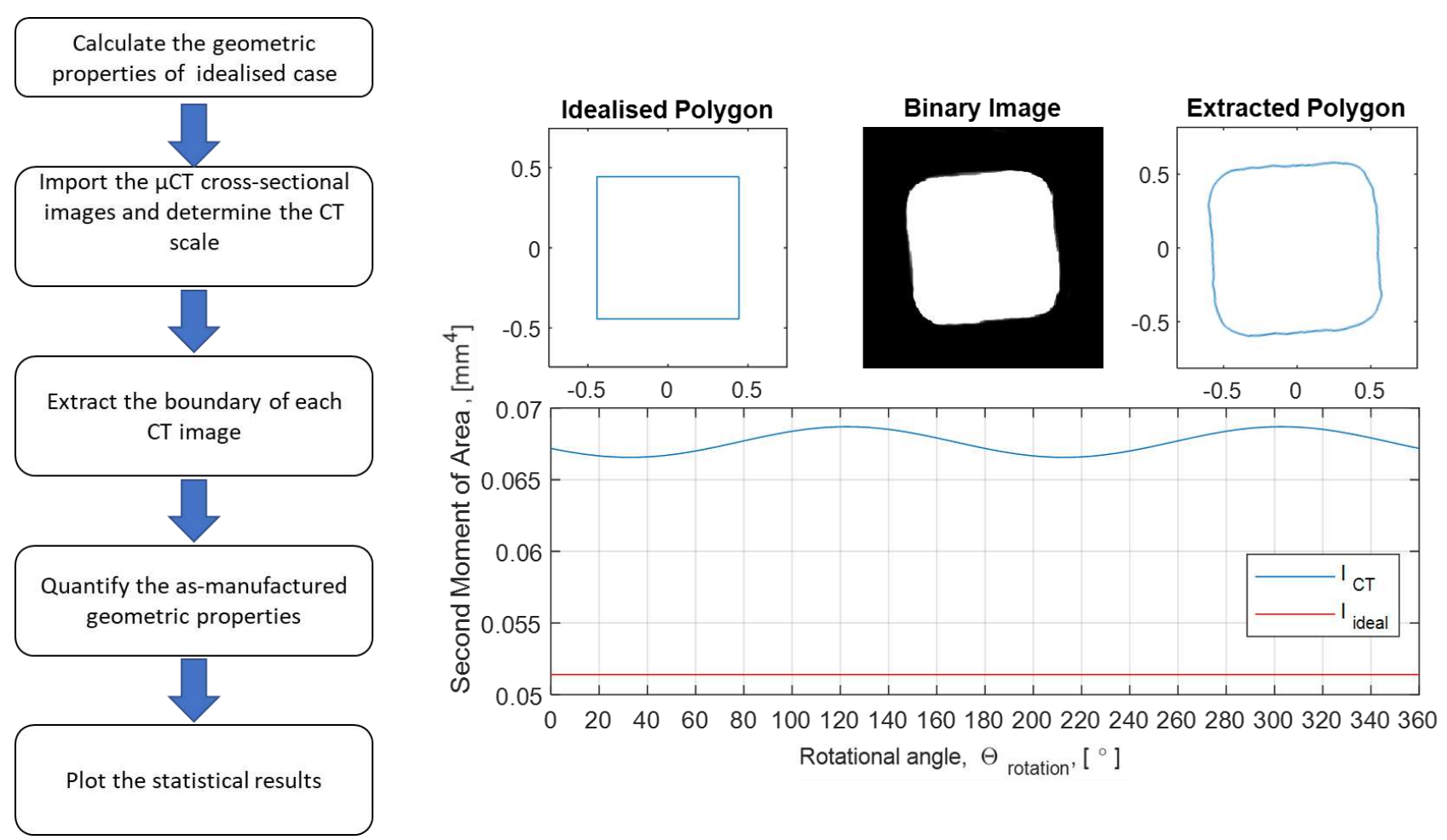

Figure 5: Algorithmic process for quantifying geometric properties of both idealised and as-manufactured cases. 


\section{RESULTS AND DISCUSSION}

This section presents the cross-sectional geometric properties of the proposed DOE for both idealised and as-manufactured cases. It is divided into six subsections: the idealised case, which demonstrates theoretically how the polygon order affects the geometric properties corresponding to the same cross-sectional area; comparison between, idealised polygon crosssectional versus as-manufactured strut elements for both material (aluminium and titanium), for the area; the second moment of area; and the radius of gyration; the final two subsections illustrates the elastic shape factor and the failure shape factor which can be used to evaluate the stiffness and strength of the as-manufactured geometry respectively.

\subsection{GEOMETRIC PROPERTIES OF IDEALISED STRUT ELEMENTS}

The stiffness and strength of strut element specimens associated with the same cross-sectional area may be characterised by quantifying the idealised geometric properties including: second moment of area, $I_{\text {ideal }}$, radius of gyration, $R_{g}$ ideal , elastic bending shape factor, $\emptyset_{B}^{e}$ ideal , section modulus, $Z_{\text {ideal }}$, and bending failure shape factor, $\emptyset_{B \text { ideal }}^{f}$.

These geometric properties are quantified (Figure 6) for various regular polygonal cross-sections associated with equal cross-sectional area, while rotated 360 degrees about the centroid, $\theta_{\text {rotation }}$. Figure $6 \mathrm{~b}-\mathrm{d}$ show that the second moment of area and radius of gyration and the elastic shape factor remain constant while rotating these idealised polygonal shapes. The elastic shape factor of octagonal cross-section has a very slight increase of $0.2 \%$ over the circular section, whereas square, and triangular shapes indicate a $4.7 \%$, and $20.9 \%$ increase, respectively. Meanwhile, the section modulus and failure shape factor show a dependence on orientation. For example, the idealised triangular cross-section these range between $23 \%$ lower and $55 \%$ higher than the circular cross-section, depending on bending load direction (Figure 6f).

These results are known in structural engineering but are not applied in the design of lattice structure elements enabled by additive manufacturing. The next subsections investigate how the as-manufactured cross-section varies from the idealised results for these important geometric characteristics. 
a)
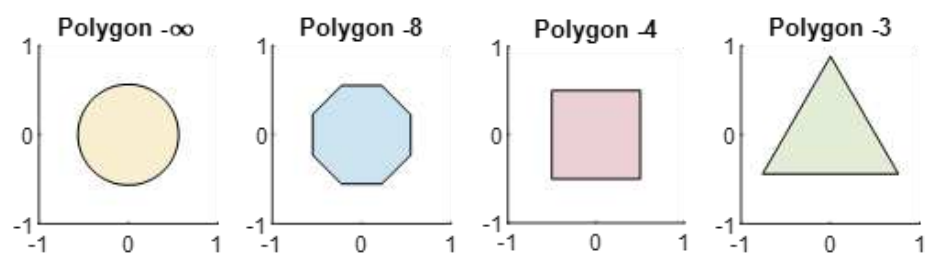

b)

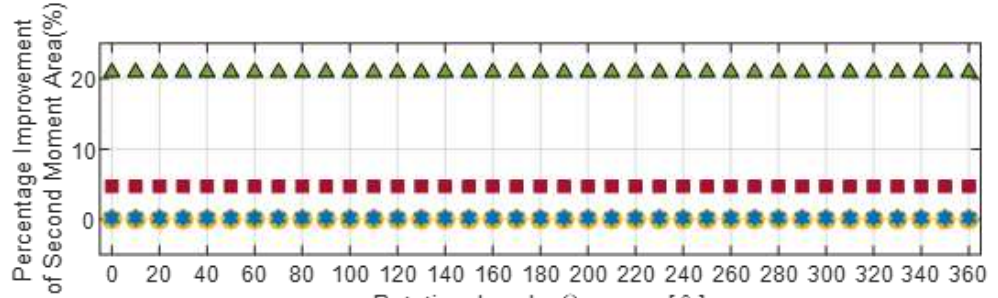

c)

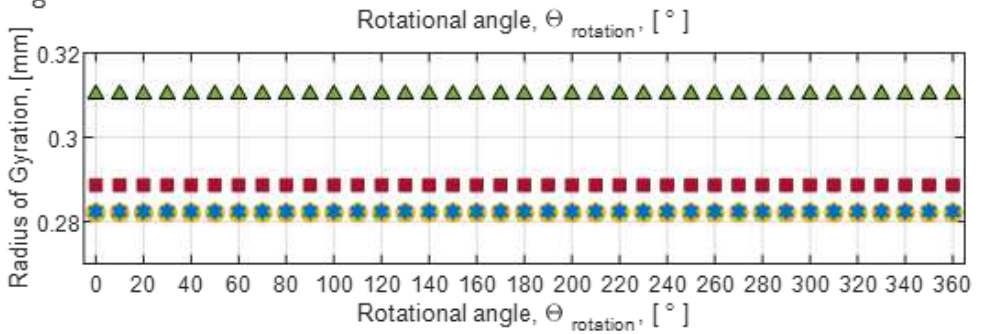

d)

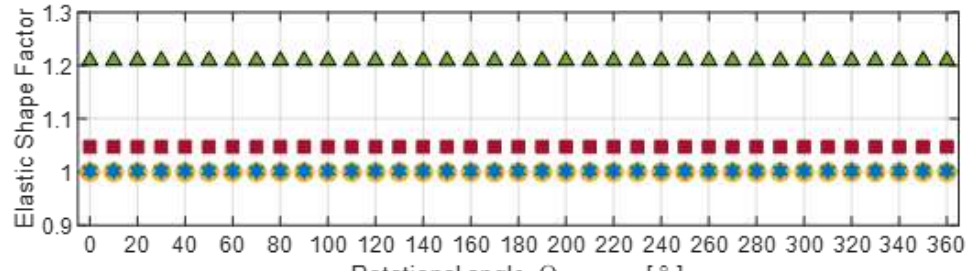

e)

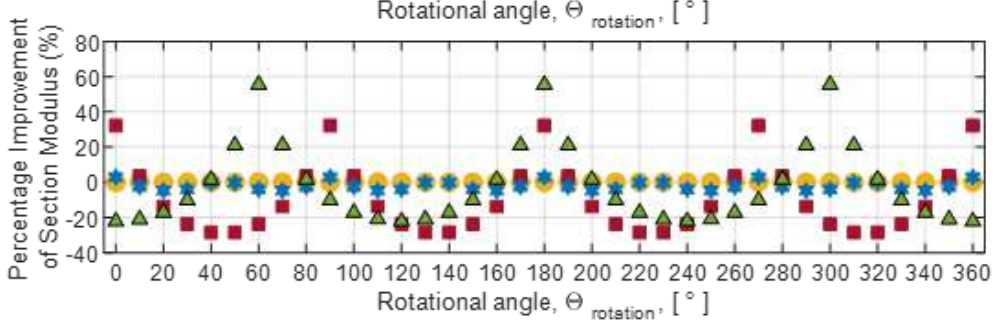

f)

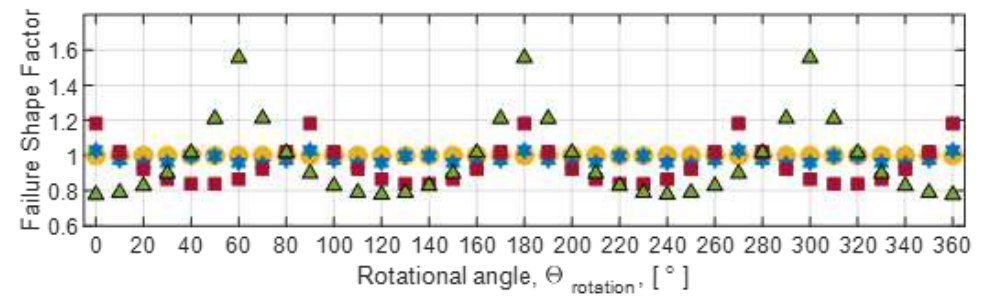

Figure 6: Idealised geometric properties subject to different polygon order while rotation,

$\boldsymbol{\theta}_{\text {rotation }}$. a) Circular, octagonal, square and triangular, associated with the same crosssectional area. b) Second moment of area percentage improvement of each shape, c) radius of gyration, d) Elastic shape factor, e) Percentage improvement of section modulus, and f) Failure shape factor. 


\subsection{IDEALISED VERSUS AS-MANUFACTURED CROSS-SECTIONAL AREA}

As-manufactured polygon cross-sectional area, $A_{C T}$, is affected by manufacturing processes, leading to variation between idealised and as-manufactured strut element. Effective diameter, $D_{\text {eff }}$, inclination angle, $\alpha$, polygon order, $p$, and material significantly affect the LB-PBF manufacturability.

Figure 7 shows the variation in cross-sectional area within each of the as-manufactured strut elements. The box-plots provide a graphical statistical summary for each cross-sectional image for the given strut. These include the rectangular box representing the interquartile range (IQR) (25\%-75\% percentiles), the whiskers extending up to $1.5 \times 1$ QR and the median as the horizontal line within the box. The plots are presented in a graphical array as defined by material (columns), effective diameter (rows), cross-sectional shape and build inclination angle (horizontal axis labels). The expected value based on the idealised shape is presented as the long horizontal lines. For consistency, each of geometric characteristics discussed in later subsections are presented using the same graphical array.

Comparing the aluminium (left column of graphs Figure 7a-d) to the titanium (right column of graphs Figure 7e-h), generally there is greater variation within the individual aluminium specimens than the titanium as indicated by the relative size of the IQR. The exception being at $D_{\text {eff }}=0.5 \mathrm{~mm}$. Furthermore, for the aluminium there is a trend that area (median) and variation in area (box plot size) increases with decreasing inclination angle.

For the titanium (Figure 7e-h) there is an upward trend in the position of the box-plots within each graph, indicating that the cross-sectional area of the strut elements increases as the shape changes from circular to triangular, i.e., as the polygon order decreases, the area increases. This suggests that more material may be accumulating in the as-manufactured triangular shape than the circular shape, even though they are intended to be the same area as indicated by the long horizontal line.

For the aluminium strut elements (Figure 7a-d), the same upward trend across the shapes is not visible, however within each shape (clusters of three) there is both a downward trend in the cross-sectional area and in the variation of the cross-sectional area with increasing build inclination angle.

These trends indicate that the cross-section area of aluminium strut elements is strongly affected by inclination, accumulating more area and greater variation in area along a strut element as the build inclination angle is decreased from $90^{\circ}$ to $35^{\circ}$. Meanwhile, the titanium strut elements show far less variation in area. 

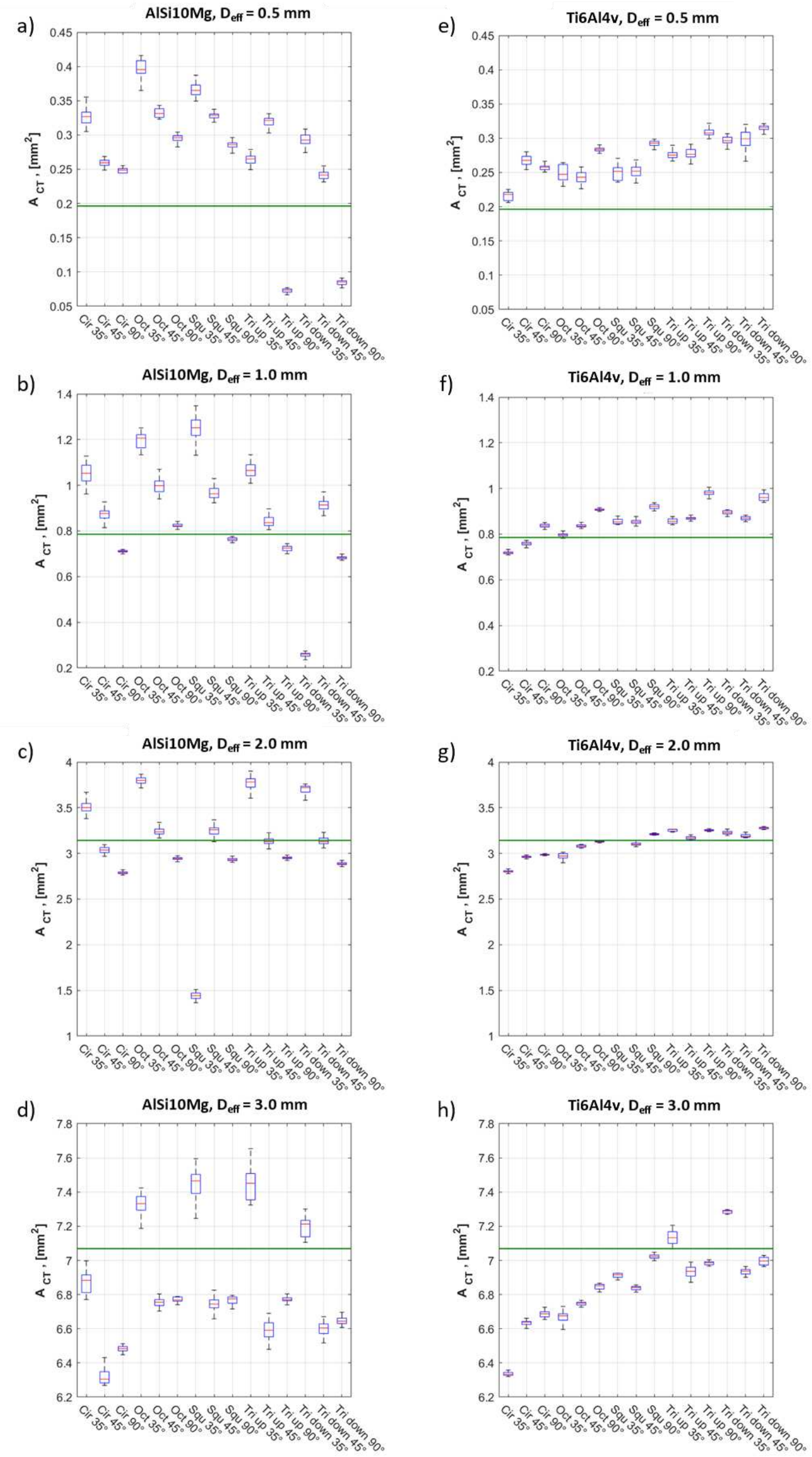
Figure 7: Box-plots of as-manufactured cross-sectional area of aluminium and titanium strut elements compared with idealised cross-sectional area (green horizontal lines). a) to d) are aluminium strut element associated with effective diameter of $0.5,1.0,2.0$, and $3.0 \mathrm{~mm}$ respectively. e) to $\mathrm{h}$ ) are titanium strut element associated with effective diameter of $0.5,1.0$, 2.0, and $3.0 \mathrm{~mm}$ respectively (outliers hidden).

\subsection{SECOND MOMENT OF AREA (IDEAL VS CT)}

The second moment of area for as-manufactured case, $I_{C T}$, is calculated based on extracted data from $\mu \mathrm{CT}$ cross-sectional images. These extracted data provide outer boundary, centroid, and asmanufactured area, $A_{C T}$, for each individual image. Each fabricated strut element contains a number of images along its length. Therefore, to quantify $I_{C T}$ with image orientation, the extracted boundary is rotated with a small incremental number of degrees $\left(3.6^{\circ}\right)$ as shown in Figure $8 \mathrm{a}$. At each rotational angle, $\theta_{\text {rotation, }}$ the $I_{C T}$ is calculated as shown in the Figure $8 \mathrm{~b}$.

a)

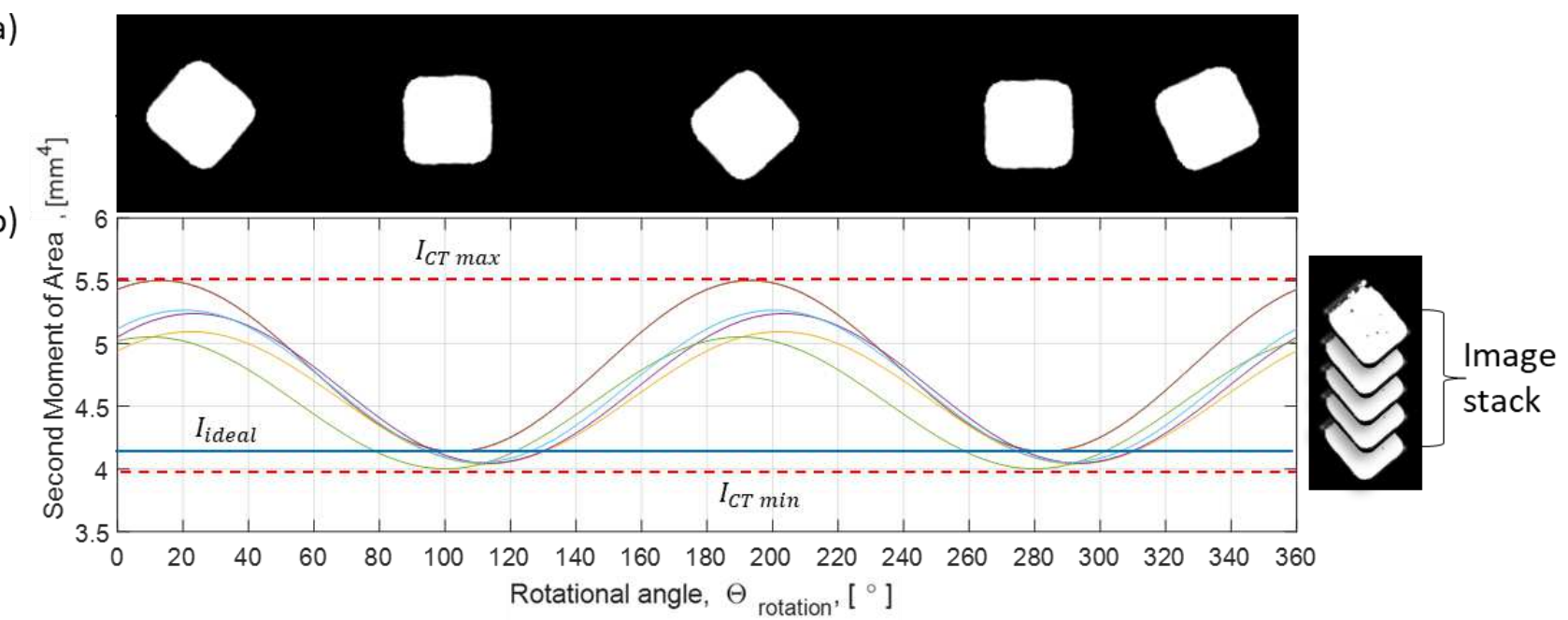

Figure 8: Maximum and minimum second moment of area of as-manufactured strut elements compared with idealised geometry. a) Cross-sectional image orientation with rotation.

b) Second moment of area for as-manufactured and idealised cases.

All the $I_{C T}$ are compared with the idealised case, $I_{\text {ideal }}$, for each strut categorized by material (AISi10Mg and Ti6Al4V), the effective diameter, $D_{\text {eff }}$, shape and inclination angle, $\alpha$, as shown in Figure 9. The distribution of second moment of area of the as-manufactured struts in the form of box-plots, using the same graphical array described in subsection 4.2. The second moment of area of the idealised strut is shown as long horizontal lines that progressively step up with changing shapes.

Comparing the aluminium and titanium struts at the same effective diameter, there is significantly more variation in $I_{C T}$ across the aluminium struts than the across the titanium struts. Suggesting that the titanium provides a more consistent stiffness. 
For the aluminium strut elements (Figure 9a-d), similar to found for $A_{C T}$, the magnitude and variation of $I_{C T}$ within the as-manufactured strut elements shows a decreasing trend with increasing build inclination. This is seen by longer IQR boxes for $35^{\circ}$ strut elements compared to the $90^{\circ}$ struts.

Considering the titanium strut elements (Figure 9e-h), the increase in $I_{C T}$ across the shapes is steeper than expected from the idealised cross-sections. This corresponds with the previous observation that the as-manufactured area, $A_{C T}$, increased with decreasing polygon order at a given $D_{e f f}$. 

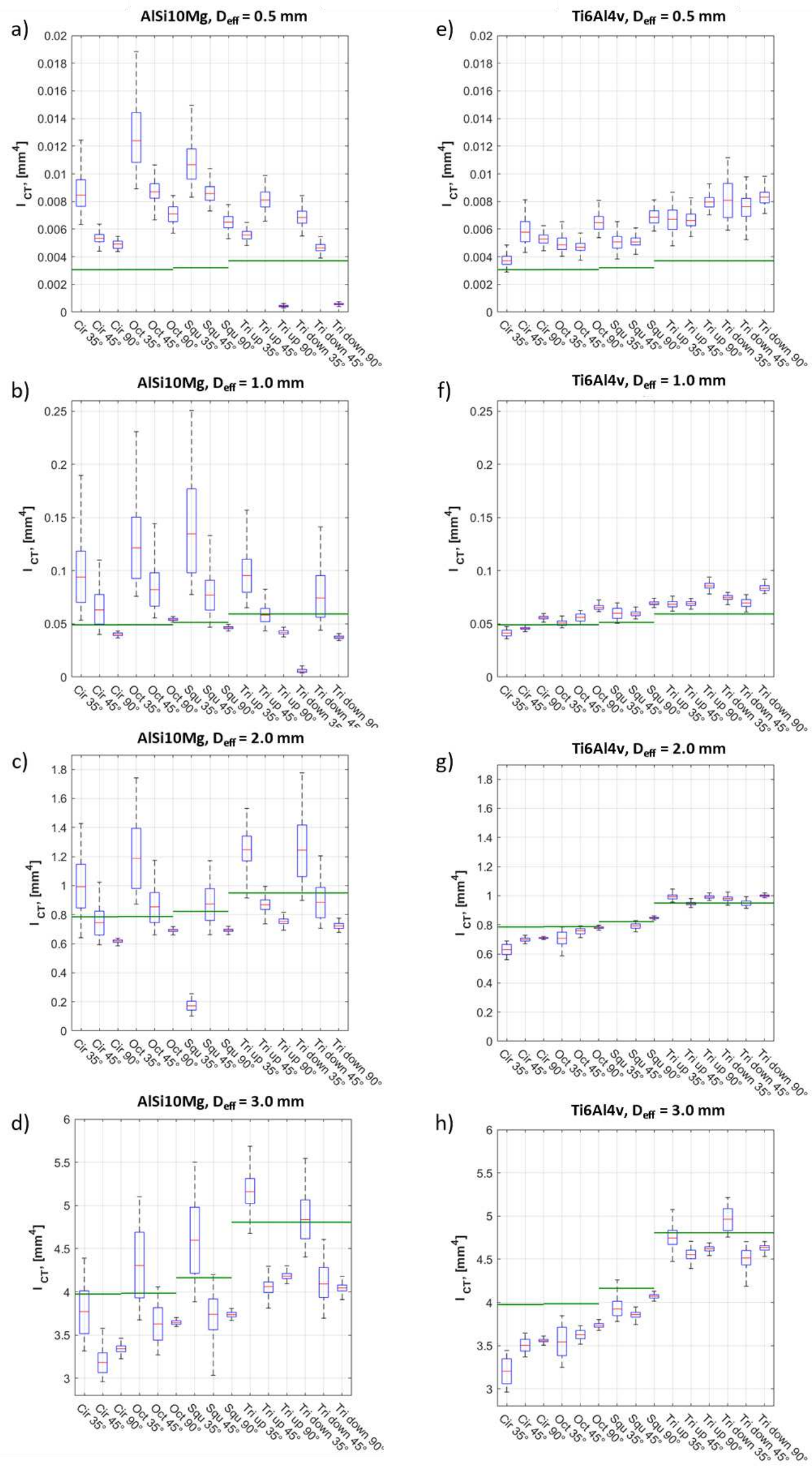
Figure 9: Box-plots of as-manufactured second moment of area of aluminium and titanium strut elements compared with idealised second moment of area (green horizontal lines). a) to d) are aluminium strut elements associated with effective diameter of $0.5,1.0,2.0$, and 3.0 $\mathrm{mm}$ respectively. e) to $\mathrm{h}$ ) are titanium strut elements associated with effective diameter of

\section{$0.5,1.0,2.0$, and $3.0 \mathrm{~mm}$ respectively (outliers hidden).}

\subsection{RADIUS OF GYRATION (IDEAL VS CT)}

The efficiency of a cross-sectional shape for elastic stability under compression can be determined via the radius of gyration, $R_{g}$, associated with the same cross-sectional area, as discussed in Section 2.2. Figure 10 shows box-plots for the radius of gyration of the asmanufactured strut elements, $R_{g C T}$, compared with the line of the idealised case, $R_{g}$ ideal, for both materials (aluminium and titanium). It compares each material individually which is useful to evaluate the efficiency of the actual shape versus the idealised shape. Figure 10 also evaluates the quality of fabrication and the effectiveness of controlling factors (e.g., inclination angle).

Overall, it can be observed that the variation in $R_{g} C T$ is larger in the aluminium strut elements (Figure $10 \mathrm{a}-\mathrm{d}$ ) than the titanium (Figure $10 \mathrm{a}-\mathrm{d}$ ).

The variation within individual aluminium strut elements is largest for the $35^{\circ}$ and $45^{\circ}$ build inclination angle, while the $90^{\circ}$ cases are similar to the titanium.

The dependence with shape observed in $A_{C T}$, of the titanium struts which carried over into $I_{C T}$ is not obvious in the radius of gyration, with relative increase in $R_{g C T}$ with $\alpha$ better matching that expected by $R_{g}$ ideal . 

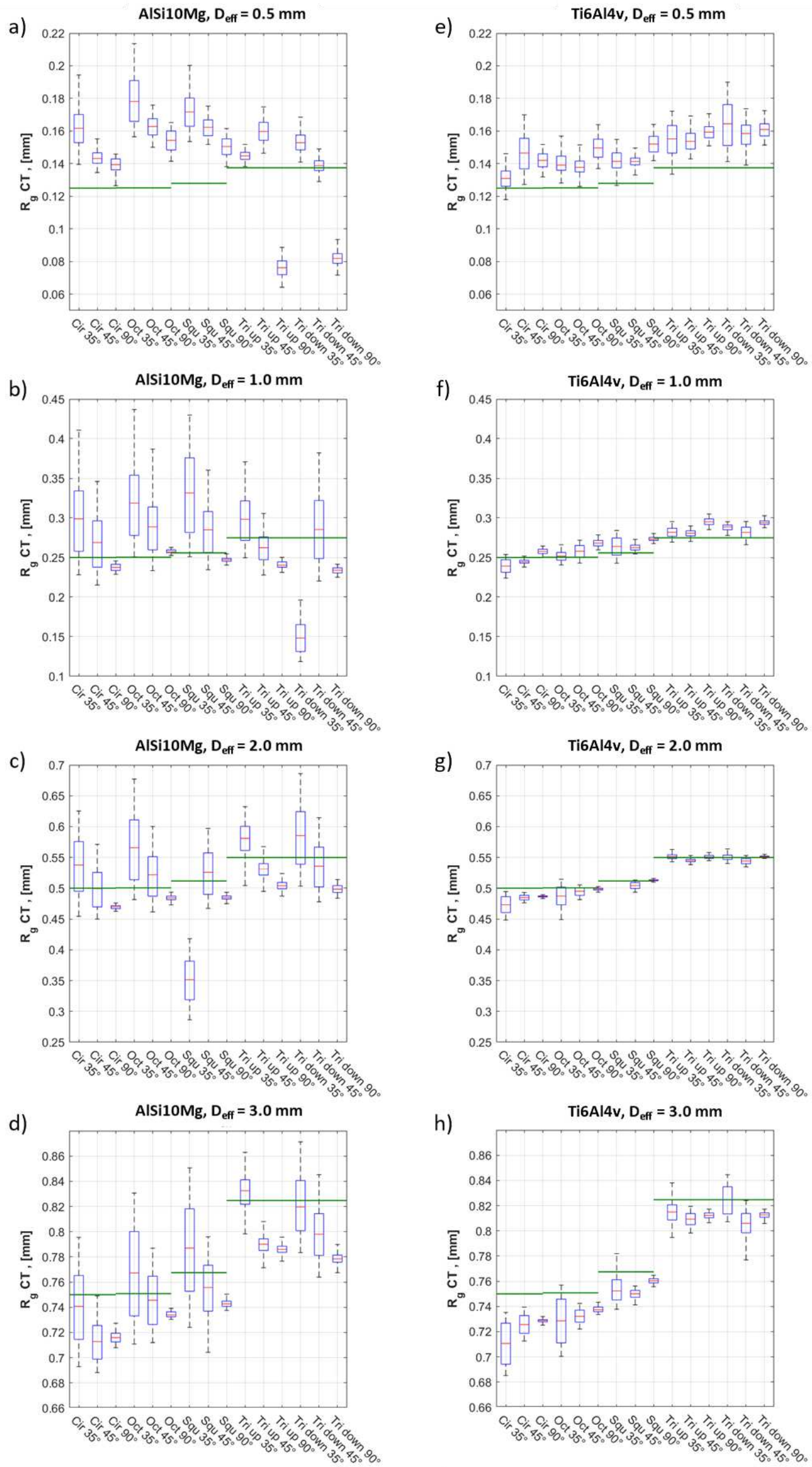
Figure 10: Box-plots for as-manufactured radius of gyration of aluminium and titanium strut elements compared with idealised radius of gyration (green horizontal lines). a) to d) are aluminium strut elements associated with effective diameter of $0.5,1.0,2.0$, and $3.0 \mathrm{~mm}$ respectively. e) to $\mathrm{h}$ ) are titanium strut elements associated with effective diameter of 0.5 ,1.0, 2.0, and $3.0 \mathrm{~mm}$ respectively (outliers hidden).

\subsection{ELASTIC SHAPE FACTOR (IDEAL VS CT)}

The elastic shape factor, $\emptyset_{B}^{e}$, provides the stiffness efficiency of the cross-sectional shape as discussed previously in Section 2.3. The as-manufactured elastic shape factor is compared with the idealised case in Figure 11. The idealised shape factor for circular section is 1.0 and for the octagonal, square, and triangular sections are 1.002, 1.047 and 1.209 respectively. Comparing the as-manufactured elastic shape factor to the idealised shape factor shows the effect of manufacturing defects and controlling factors. There is an orientational dependence corresponding with that in the second moment of area. The shape factor removes size dependence so comparison can be made purely on the achieved shape and not whether more or less material is contributing to the change.

Comparing the elastic shape factor for aluminium (Figure 11a-d) and for titanium (Figure 11e-h), generally there is less variability within individual titanium strut elements than within individual aluminium strut elements, as can be seen by the size of the IQR for individual box-plots. This is most notable in the $35^{\circ}$ and $45^{\circ}$ cases. The exception appears to be in the smaller $D_{\text {eff }}=0.5 \mathrm{~mm}$ strut elements where the titanium and aluminium both show relatively large variation in $\emptyset_{B}^{e}$.

Also, at lower effective diameters the elastic shape factors of the as-manufactured triangular cross-sections are producing results more in line with a circular cross-section. While at higher effective diameters the elastic shape factor of the as-manufactured strut elements better matches the idealised result. The transition for this occurs at $D_{e f f}=1.0 \mathrm{~mm}$ for the titanium, but between $D_{e f f}=2.0 \mathrm{~mm}$ and $3.0 \mathrm{~mm}$ for the aluminium.

Another observation is that the median $\emptyset_{B}^{e}$ for each titanium strut element sits at or below the ideal value, however in the aluminium and particularly at $D_{\text {eff }}=1.0 \mathrm{~mm}$ and $2.0 \mathrm{~mm}$, the median $\emptyset_{B}^{e}$ for the inclined circular, octagonal and square cross-sections sit above their ideal values. This appears to be an indication of as-manufactured defects that could increase local stiffness if they align favourably with loading conditions. 

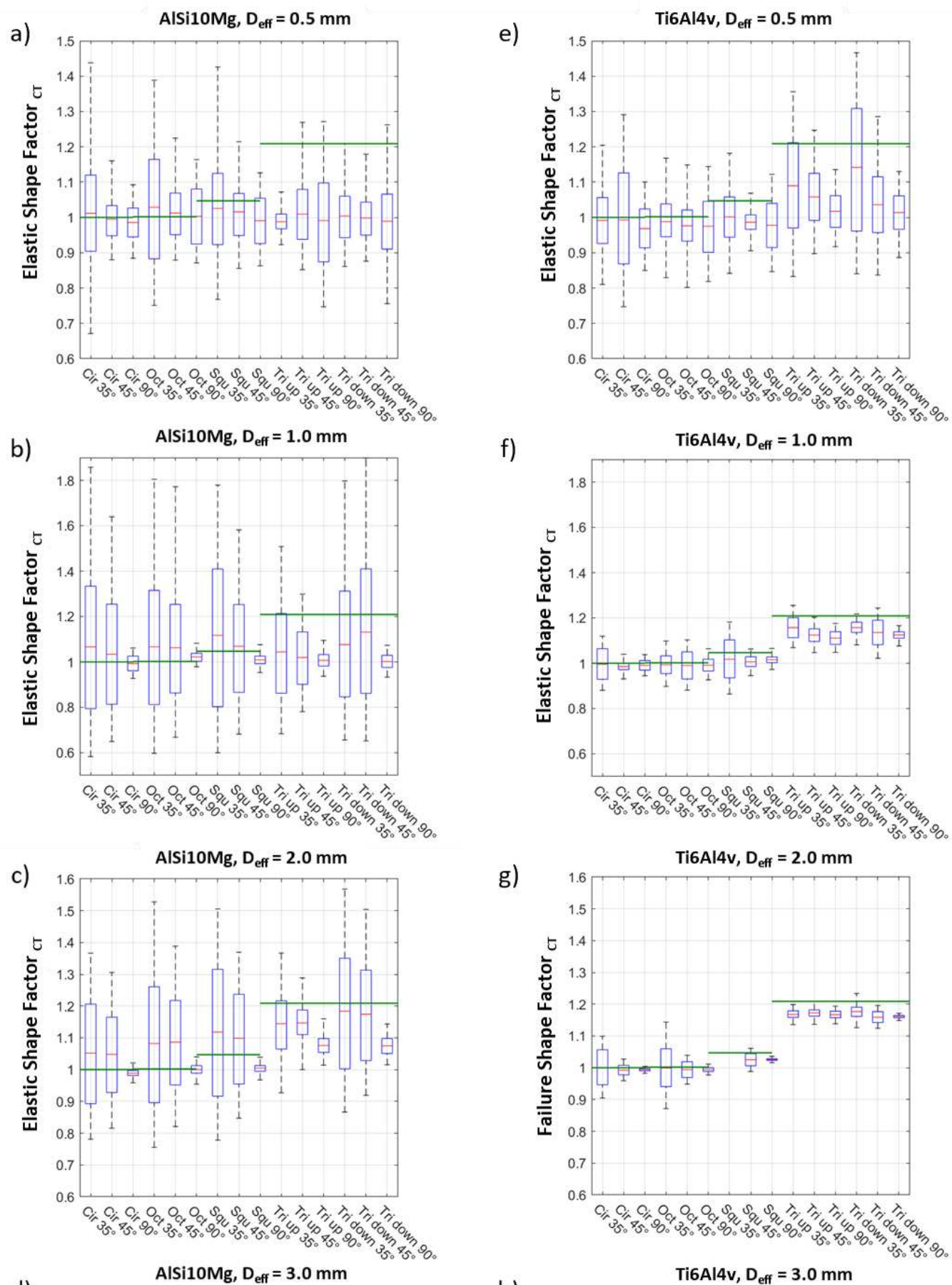

g)
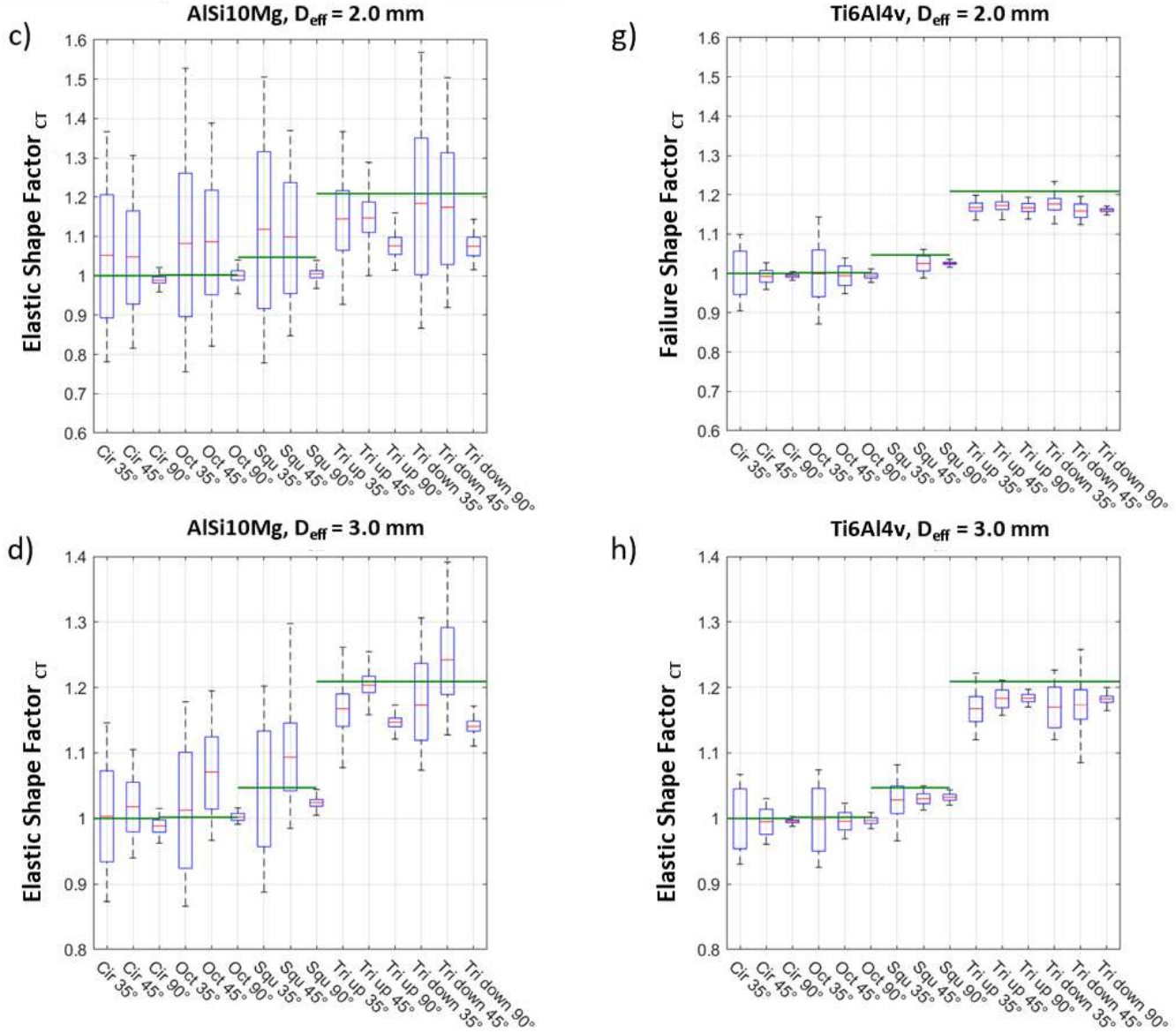
Figure 11: Box-plots of as-manufactured elastic shape factor of aluminium and titanium strut elements compared with idealised elastic shape factor (green horizontal lines). a) to d) are aluminium strut elements associated with effective diameter of $0.5,1.0,2.0$, and $3.0 \mathrm{~mm}$ respectively. e) to $\mathrm{h}$ ) are titanium strut elements associated with effective diameter of 0.5 ,1.0, 2.0, and $3.0 \mathrm{~mm}$ respectively (outliers hidden).

\subsection{FAILURE SHAPE FACTOR (IDEAL VS CT)}

The failure shape factor, $\emptyset_{B}^{f}$, can be used to evaluate the manufacturability of a strut element cross-section. The theoretical idealised failure shape factor for a circular cross-section is 1.0 and for the octagonal, square, and triangular cross-sections, there is an orientation dependence which range between the values (0.95-1.029), (0.83-1.18), and (0.77-1.55) respectively. The failure shape factor for the as-manufactured aluminium and titanium strut elements are compared to the ideal ranges in Figure 12.

Comparing the aluminium (Figure 12a-d) and titanium (Figure 12e-h) cases, the titanium strut elements show greater consistency for a given shape across the three inclination angles, and for the square and triangular shapes tend to sit inside the ideal range, with the distributions better matching the ideal range with increasing effective diameter. On the other hand, the aluminium struts show greater variation, which is particularly apparent for circular and octagonal shapes.

The implication of the large variation in the failure shape factor is that it shows both an opportunity for improved strength when geometric orientation can better support the loading conditions, but also a reduction in strength if the lesser geometric orientation is exposed by the loading condition. An important observation from these graphs is that the median result typically sits below 1.0, meaning that more orientations fall into the scenario of reduced strength rather than improved strength if the cross-section orientation and loading were randomly aligned. 

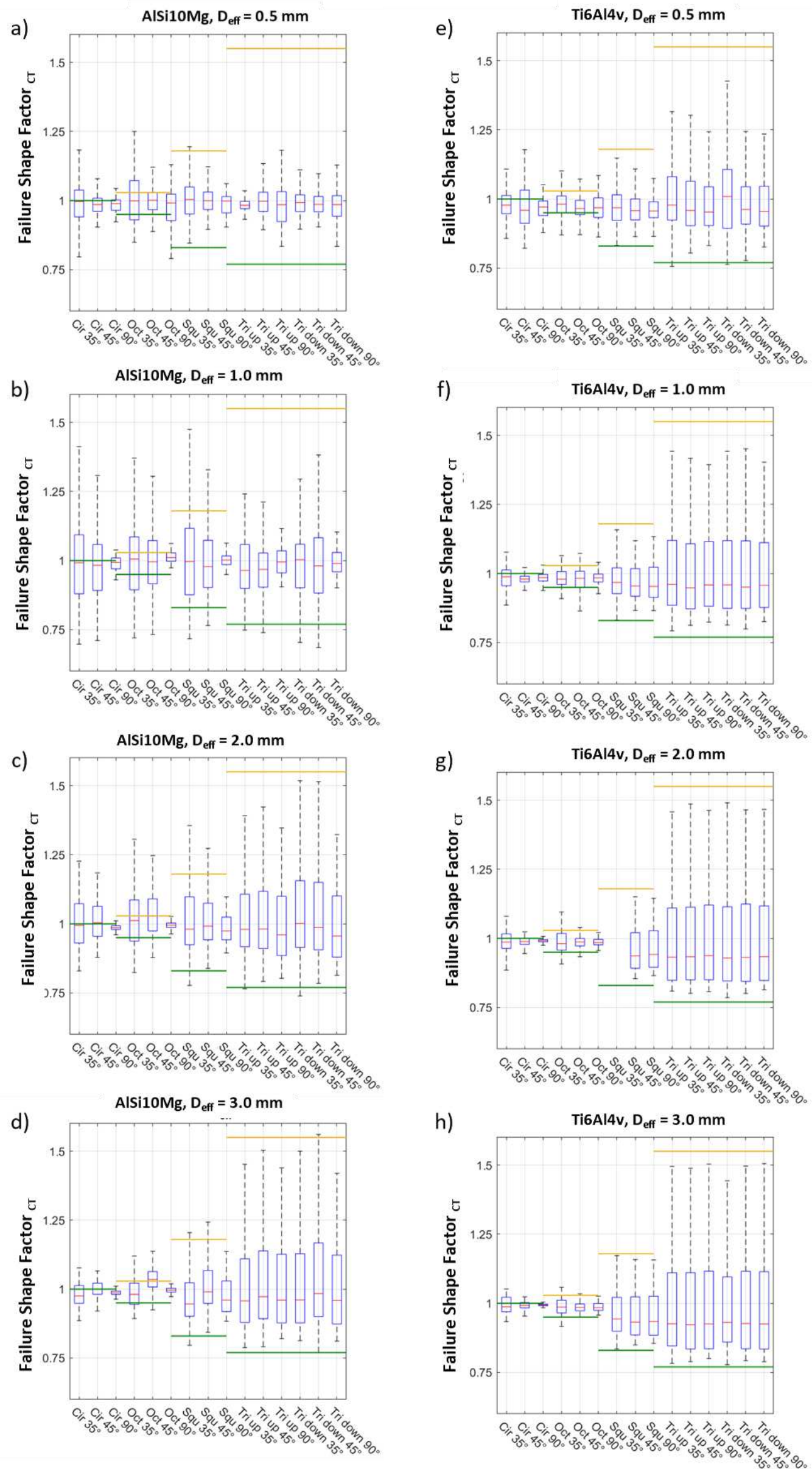
Figure 12: Box-plots of as-manufactured failure shape of aluminium and titanium strut elements compared with range of idealised failure shape factor (green and orange horizontal lines). Green and orange horizontal lines are the lower and upper idealised failure shape factor respectively. a) to d) are aluminium strut elements associated with effective diameter of $0.5,1.0,2.0$, and $3.0 \mathrm{~mm}$ respectively. e) to $\mathrm{h}$ ) are titanium strut elements associated with effective diameter of $0.5,1.0,2.0$, and $3.0 \mathrm{~mm}$ respectively (outliers hidden).

\section{Discussion}

Structural mechanics theory suggests that square and triangular cross-sections provide structural efficiency over the circular cross-section, with elastic shape factors of 1.05 and 1.21, respectively. This suggests an opportunity for improved stiffness simply through choice of more efficient crosssectional shapes. At the same cross-sectional area, the second moment of area is the important parameter when considering bending stiffness and buckling resistance. As the cross-section becomes irregular, by design or through as-manufactured variation, the second moment of area and the elastic shape factor becomes orientation dependent, therefore the stiffness response will be orientation dependent.

For strength in bending of the same cross-sections, the stress in the outermost fibres becomes important. For an axisymmetric geometry (circular or tubular cross-section) the distance to the outermost fibre, $y_{\max }$, is independent of orientation, however for other cross-sections, including the regular polygon shapes, there is an orientation dependence of $y_{\max }$, and in turn the failure shape factor. This orientation dependence of the failure shape factor can be exacerbated by variation in the as-manufactured shape.

To ensure the as-manufactured variation does not degrade stiffness or strength, it is important to understand how design and manufacturing parameters influence the as-manufactured shape.

In this research, the variation of the as-manufactured cross-sectional shape was observed for material, effective diameter, build inclination angle and for a set of idealised polygons:

- A material dependence was seen, with the titanium typically producing much less variability in the measured geometric characteristics than the aluminium. Suggesting the cross-sections were more consistent along the length of the titanium strut elements.

- However, the titanium strut elements had an unexpected but measurable increase in asmanufactured cross-sectional area with decreasing polynomial order (circle- $\infty$, octagon- 8 , square-4, triangle-3).

- Meanwhile, in the aluminium strut elements a strong dependence on inclination angle was observed. With increased cross-sectional area and increased variation in cross-sectional area observed for lower inclination angles. These trends were also seen in the second moment of area and carried over to influence variation in the shape factors. 
- As the effective diameter increases, the square and triangular cross-sections distinguish themselves by matching up with their expected value in the elastic shape factor and even more so matching their range for the failure shape factor. This is particularly evident for the titanium strut elements.

- Previous research on the data has shown that there is a manufacturability limit to the effective diameters, below which the different shapes were not able to be distinguished [5]. The effect of this can be seen in the shape factors for the aluminium strut elements at $D_{\text {eff }}=$ $0.5 \mathrm{~mm}$ and $1.0 \mathrm{~mm}$, where the variation in shape factors across the different shapes cannot be distinguished by their shape.

To determine whether alternative cross-sectional shapes are appropriate replacements for lattice strut elements depends upon the desired performance and the amount of manufacturing defects that can be tolerated. For the titanium strut elements, with the exception of the smallest example $\left(D_{e f f}=0.5 \mathrm{~mm}\right)$ the elastic shape factor of the as-manufactured triangular cross-section are $10-20 \%$ above the ideal circular cross-section, short of the $21 \%$ improvement predicted by the ideal case. This suggests that the resistance to elastic bending and to elastic buckling should be improved by switching to the triangular cross-section. In the aluminium, similar benefits are only realised at $D_{e f f}=3.0 \mathrm{~mm}$.

On the other-hand, when considering the failure shape factor, which is related to the onset of yield, some of the as-manufactured cross-sections come close to realising the upper values of $18 \%$ and $55 \%$ improvement for the square and triangular shapes respectively. However, these results are specific to the most favourable orientations, and yet the majority of the cross-sections and orientations provide for failure shape factors that are less than the circular cross-section. This highlights that the square and triangular cross-sections are not well suited to improving strength, unless the best orientation can be achieved to support the loads. While unknown or complex loading is likely to expose the weaker orientations.

There are future opportunities to extend the methodology and analysis to other loading cases, other cross-sections and other materials. The current work considered the elastic shape factor (suitable for elastic bending and buckling resistance) and the failure shape factor (suitable for bending failure) as these are often considered as the dominant behaviours in lattice structures under compression. There are also shape factors related to torsion which could be considered for more complex loading cases. These could lead to investigation of alternative cross-sections that provide structural efficiencies, such as channels and hollow sections. Furthermore, the methodology can be applied to investigate manufacturability and as-manufactured structural efficiency of other AM systems and materials. 


\section{CONCLUSION}

Additive Manufacturing (AM) using Laser-Based Powder Bed Fusion (LB-PBF) methods allows fabrication of highly complex lattice geometries. These structures provide structurally efficient solutions for high-value applications such as medical implants and aerospace components. However, LB-PBF processes inherently incur manufacturing variation and defects that lead to dimensional variation between the idealised and as-manufactured specimens. This research developed a design tool to algorithmically quantify the structural impact of as-manufactured geometrical defects.

The as-manufactured strut elements were recorded using micro-computed tomography $(\mu \mathrm{CT})$ imaging and then reconstructed into a sequence of as-manufactured strut element crosssectional images. The geometric properties, including as-manufactured area, second moment of area, elastic and failure shape factors, are quantified using the proposed method and verified against idealised cases.

The methodology was applied to a set of strut elements additively manufactured using two materials (aluminium and titanium), with varying effective diameter, polygon order, inclination angle and section shape. The following key observations were made:

- The idealised second moment of area of square and triangle cross-sections have $5 \%$ and $21 \%$ improvement respectively compared to idealised circular or octagonal shapes. This suggests increased elastic buckling and bending resistance of fabricated strut elements.

- Additionally, the second moment of area of circular and octagonal cross-sections differ by only $0.2 \%$. Showing that increasing the polygon order more than eight does not significantly affect the second moment of area. This implies that further increase in polygon order is ineffectual at increasing the second moment of area (although larger polygons are typically associated with larger data file size).

- Generally, it was found that the variation between $I_{C T}$ and $I_{\text {ideal }}$ in aluminium is greater than in titanium which indicates titanium has less manufacturing defects. These variations are increased with lower inclination angles due to manufacturing defects.

- Effective diameter, $D_{\text {eff }}$, has a major impact on manufacturability of the strut elements, particularly on aluminium at $0.5 \mathrm{~mm}$, where it is observed that the polygon order is not contributing any differences on $I_{C T}$. Meanwhile titanium maintains the polygon shape with fewer manufacturing defects (even for relatively small effective diameters).

- Elastic and failure shape factors are useful to determine the manufacturability of different polygons cross-sections. Generally, as the effective diameter increased the as manufactured shape factors, $\emptyset_{C T}$, distributions were more closely aligned with the range of there idealised values, $\emptyset_{\text {ideal }}$, indicating better realisation of the intended shapes. The titanium shows this 
improvement in both shape factors with each incremental increase in effective diameter. The aluminium shows poor replication of the shape factor at all but the largest effective diameter.

- For all cases the as-manufactured elastic and failure shape factors are below that of the idealised cases, meaning that designers should be aware that the as-manufactured strut performance will typically be below that anticipated by the idealised cross-section.

The proposed methodology can be applied as a Design for AM (DFAM) tool for any AM systems and materials.

\section{ACKNOWLEDGMENTS}

The authors acknowledge use of facilities with in RMIT Advanced Manufacturing Precinct and the RMIT Microscopy and Microanalysis Facility. (https://www.rmit.edu.au/about/our-locationsand-acilities/facilities/researchfacilities/advanced-manufacturing-precinct).

\section{FUNDING}

The authors declare that no funds, grants, or other support were received during the preparation of this manuscript.

\section{AVAILABILITY OF DATA AND MATERIAL}

The data is available and only can be provided by request of the journal.

\section{CODE AVAILABILITY}

The code is available and only can be provided by request of the journal.

\section{DECLARATIONS}

Ethics approval: Not applicable.

Consent to participate: Not applicable.

Consent for publication: Not applicable.

Competing interests: The authors declare no competing interests.

\section{REFERENCES}

[1] S. H. Huang, P. Liu, A. Mokasdar, and L. Hou, "Additive manufacturing and its societal impact: a literature review," Int J Adv Manuf Technol, vol. 67, no. 5, pp. 1191-1203, 2013, doi: 10.1007/s00170-012-4558-5.

[2] M. M. Martin Leary, Hugh Williams, Eric Yang, Ahmad Alghamdi, , X. Z. Bill Lozanovski, Darpan Shidid, Lena Farahbod-Sternahl, , and I. K. Gerd Witt, Peter Choong, Ma 
Qian, Milan Brandt, "Inconel 625 Lattice Structures Manufactured By Selective Laser Melting (SLM): Mechanical Properties, Deformation and Failure Modes," (in English), Mater. Des., vol. 157, pp. 179-199, Nov 5 2018, doi: 10.1016/j.matdes.2018.06.010.

[3] J. Mun, J. Ju, and J. Thurman, "Indirect additive manufacturing based casting (I AM casting) of a lattice structure," in ASME International Mechanical Engineering Congress and Exposition, Proceedings (IMECE), 2014, vol. 2A, doi: 10.1115/IMECE2014-38055.

[4] W. E. Frazier, "Metal Additive Manufacturing: A Review," Journal of Materials Engineering and Performance, journal article vol. 23, no. 6, pp. 1917-1928, June 01 2014, doi: 10.1007/s11665-014-0958-z.

[5] A. Alghamdi, "Effect of polygon order on additively manufactured lattice structures: a method for defining the threshold resolution for lattice geometry," The International Journal of Advanced Manufacturing Technology, 20192019.

[6] M. Leary et al., "Inconel 625 lattice structures manufactured by selective laser melting (SLM): Mechanical properties, deformation and failure modes," Materials \& Design, vol. 157, pp. 179-199, 2018.

[7] B. Lozanovski et al., "Computational modelling of strut defects in SLM manufactured lattice structures," (in English), Materials \& Design, vol. 171, Jun 5 2019, doi: ARTN 107671 10.1016/j.matdes.2019.107671.

[8] B. Lozanovski et al., "Computational modelling of strut defects in SLM manufactured lattice structures," Materials \& Design, p. 107671, 2019.

[9] D. Downing, M. Leary, M. McMillan, A. Alghamdi, and M. Brandt, "Heat transfer in lattice structures during metal additive manufacturing: numerical exploration of temperature field evolution," Rapid Prototyping Journal, vol. 25, no. 5, pp. 911-928, 2020.

[10] B. Zhang, Y. Li, and Q. Bai, "Defect Formation Mechanisms in Selective Laser Melting: A Review," Chinese Journal of Mechanical Engineering, vol. 30, no. 3, pp. 515-527, 2017, doi: 10.1007/s10033-017-0121-5.

[11] I. Echeta, X. Feng, B. Dutton, R. Leach, and S. Piano, "Review of defects in lattice structures manufactured by powder bed fusion," The International Journal of Advanced Manufacturing Technology, pp. 1-20, 2019.

[12] A. Alghamdi, T. Maconachie, D. Downing, M. Brandt, M. Qian, and M. Leary, "Effect of additive manufactured lattice defects on mechanical properties: an automated method for the enhancement of lattice geometry," The International Journal of Advanced Manufacturing Technology, pp. 1-15, 20202020. 
[13] M. Bächle and R. J. Kohal, "A systematic review of the influence of different titanium surfaces on proliferation, differentiation and protein synthesis of osteoblast-like MG63 cells," Clinical oral implants research, vol. 15, no.6, pp.683-692\%@ 0905-7161, 2004.

[14] N. A. Fleck, New Approaches to Structural Mechanics, Shells and Biological Structures kluwer (New Approaches to Structural Mechanics, Shells and Biological Structures). Springer Netherlands : Imprint: Springer (in English), 2002.

[15] V. S. Deshpande, N. A. Fleck, and M. F. Ashby, "Effective properties of the octet-truss lattice material," Journal of the Mechanics and Physics of Solids, vol. 49, no. 8, pp. 1747-1769, 2001.

[16] D. Kang, S. Park, Y. Son, S. Yeon, S. H. Kim, and I. Kim, "Multi-lattice inner structures for high-strength and light-weight in metal selective laser melting process," Materials \& Design, vol. 175, p. 107786, 2019.

[17] A. Alghamdi et al., "Effect of polygon order on additively manufactured lattice structures: a method for defining the threshold resolution for lattice geometry," Int J Adv Manuf Technol, vol. 105, pp. 2501-2511, October 2019 2019, doi: 10.1007/s00170-019-04168-1.

[18] M. Clifford, K. Simmons, and P. Shipway, An introduction to mechanical engineering: Part 1. CRC Press, 2009.

[19] R. Gentle, P. Edwards, and W. Bolton, "Mechanical engineering systems," Elsevier, 2001, ch. 5, pp. 261-265.

[20] D. Hally, "Calculation of the Moments of Polygons," DEFENCE RESEARCH ESTABLISHMENT SUFFIELD RALSTON (ALBERTA), 1987.

[21] J. Ochshorn, Structural elements for architects and builders. Elsevier, 2009.

[22] M. F. Ashby, \& Cebon, D., "Materials selection in mechanical design," Le Journal de Physique IV, vol. 3, no. C7, pp. C7-1, 1993. 